\title{
Determination of dehydroepiandrosterone in dietary supplements by reversed-phase HPLC
}

\author{
Yahia Z Tabaza ${ }^{1 *}$, Kamal M Mansi², Hanan A Azzam³ ${ }^{3}$ Farah F Al-Mamoori', Ali \\ M Al-Samydai ${ }^{4}$, Talal A Aburjai ${ }^{1}$ \\ ${ }^{1}$ Department of Pharmaceutical Sciences, School of Pharmacy. The University of Jordan, Amman 11942, ${ }^{2}$ Department of \\ Medical Laboratory Science, Faculty of Science, Al al-Bayt University, PO Box 130040, Mafraq 25113, ${ }^{3}$ Hamdi Mango Center \\ for Scientific Research, The University of Jordan, Amman 11942, Jordan, ${ }^{4}$ Pharmacological and Diagnostic Research Centre, \\ Faculty of Pharmacy, Al-Ahliyya Amman University, Amman, Jordan
}

*For correspondence: Email: y.tabaza@ju.edu.jo, aburjai@ju.edu.jo; Tel: +962-6-5355000; Fax: +962-6-5300250

Sent for review: 18 August 2020

Revised accepted: 16 January 2021

\begin{abstract}
Purpose: To develop a reversed phase high performance liquid chromatography (HPLC) method for the determination of dehydroepiandrosterone (DHEA) in dietary supplements.

Methods: A reversed-phase high performance liquid chromatography (HPLC) method was developed for the determination of DHEA in dietary supplements. An isocratic system consisting of methanol and water $(70: 30 \mathrm{v} / \mathrm{v})$ was run at a flow rate of $1 \mathrm{~mL} / \mathrm{min}$ on a $\mathrm{C} 18 \mathrm{HPLC}$ column to achieve the separation. The method was validated with regard to linearity, intra-day and inter-day precision, and limits of both detection and quantification.

Results: The method achieved a retention time of $10.8 \mathrm{~min}$, a resolution of 4.12 , a detection limit (LOD) of $50 \mathrm{ng} / \mu \mathrm{L}$, a quantification limit (LOQ) of $166.7 \mathrm{ng} / \mu \mathrm{L}$ and a label claim of $108.6 \%$ with a relative standard deviation (RSD) of $0.38 \%$ over a range of $0.0625-0.50 \mathrm{mg} / \mathrm{mL}$ with a correlation coefficient of 0.9997 .

Conclusion: The method is simple, cost effective, time-saving and reliable for determining DHEA when compared to other reported methods in literature. Thus, it will be of benefit to manufacturers of this dietary supplement to adopt the method for quantitative laboratory analysis.
\end{abstract}

Keywords: Dehydroepiandrosterone, Prasterone, Dietary supplement, HPLC, Method development, Validation

\begin{abstract}
This is an Open Access article that uses a fund-ing model which does not charge readers or their institutions for access and distributed under the terms of the Creative Commons Attribution License (http://creativecommons.org/licenses/by/4.0) and the Budapest Open Access Initiative (http://www.budapestopenaccessinitiative.org/read), which permit unrestricted use, distribution, and reproduction in any medium, provided the original work is properly credited.

Tropical Journal of Pharmaceutical Research is indexed by Science Citation Index (SciSearch), Scopus, International Pharmaceutical Abstract, Chemical Abstracts, Embase, Index Copernicus, EBSCO, African Index Medicus, JournalSeek, Journal Citation Reports/Science Edition, Directory of Open Access Journals (DOAJ), African Journal Online, Bioline International, Open-J-Gate and Pharmacy Abstracts
\end{abstract}

\section{INTRODUCTION}

Dehydroepiandrosterone (DHEA; Figure 1), also known as Prasterone, is a major endogenous steroid hormone that functions mainly as a metabolic intermediate in the biosynthesis of androgenic and estrogenic sex steroids [1]. The production of DHEA is highly affected by age as it reaches its peak between the ages of 20 and 30. After that, it steadily declines and by the ages of 70 to 80 , DHEA levels drops to about $10-20$ $\%$ of what it usually is in a young adult [2]. 


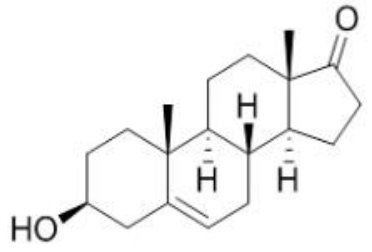

Figure 1: The structure of dehydroepiandrosterone (DHEA)

In 1934, DHEA was isolated, for the first time, from human urine. After the passage of the Dietary Supplement and Health Education Act (DSHEA) of 1994, the availability of DHEA as a naturally occurring dietary supplement has increased [1]. DHEA supplementation energizes athletes and people that perform regular physical activities, improves memory, enhances concentration and attention, activates the immune system and increases testosterone levels [3]. DHEA is available commercially in the form of tablets and capsules, with a dosage that ranges from 5 to $100 \mathrm{mg}$ of DHEA, with 25 and $50 \mathrm{mg}$ being the most common doses. The available formulae of DHEA could include it as a sole active ingredient, or it could be combined with other steroidal or vitamin supplements. Moreover, DHEA could be combined with some herbal extracts, such as gingko, ginseng and yohimbine [1].

The detection of DHEA and its metabolites in biological fluids is usually carried out using gas chromatography-mass spectrometry (GC-MS) and liquid chromatography-mass spectrometry (LC-MS) [4-7]. However, for determining DHEA in food additives, high performance liquid chromatography (HPLC) is frequently utilized $[8,9]$. However, most of the HPLC methods that are currently applied rely on normal stationary phases or buffer solutions as mobile phases and as such, they are expensive, non-versatile and complicated $[10,11]$. This work implements a reversed phase-HPLC method for the assay of DHEA in dietary supplements, aiming to save time, cost, and effort in the analysis.

\section{EXPERIMENTAL}

\section{Samples and reagents}

Dehydroepiandrosterone standard was obtained from Sigma (St Louis, MO, USA). The dietary supplement, 10 bottles of DHEA $50 \mathrm{mg}$ tablets from three different batches were obtained from American Health and Wellness Pharma (AHW) (NC, USA). Deionized Water (LabChem ${ }^{\circledR}$, USA) and HPLC-grade methanol (fulltime ${ }^{\circledR}$, China) were used as solvents for the mobile phase.

\section{Instrumentation}

The HPLC instrument DIONEX UltiMate ${ }^{T M} 3000$ was obtained from Thermo Fisher Scientific, Waltham, MA, USA and is composed of an ultraviolet-visible detector, a pump, an autosampler and uses the Chromeleon ${ }^{\mathrm{TM}} 6.0$ software. The ultrasonic water bath was purchased from JeioTech ${ }^{\circledR}$, Korea.

\section{Chromatographic conditions}

An isocratic reversed phase HPLC separation was carried out using a mobile phase of methanol and water $(70: 30 \mathrm{v} / \mathrm{v})$ and a C18 column (Eurospher-100, $150 \mathrm{~mm} \times 4.6 \mathrm{~mm}$, $5 \mu \mathrm{m})$ with a flow rate of $1 \mathrm{~mL} / \mathrm{min}$. The elution system was set at a wavelength of $210 \mathrm{~nm}$ and with an injection volume of $20 \mu \mathrm{L}$.

\section{Test solutions}

\section{Preparation of the standard solutions of DHEA}

A $0.5 \mathrm{mg} / \mathrm{mL}$ stock solution of DHEA was prepared by dissolving DHEA in the prepared mobile phase (methanol:water 70:30 v/v) followed by sonication for 5 minutes. Then, a series of DHEA solutions with concentrations of $0.5,0.25,0.125$, and $0.0625 \mathrm{mg} / \mathrm{mL}$ were prepared by diluting the stock solution with the same solvent. Thereafter, the resulting solutions were filtered through a membrane filter with a pore size of $0.45 \mu \mathrm{m}$ before being injected into the HPLC instrument.

\section{Preparation of DHEA test solution}

Five tablets, each containing a $50 \mathrm{mg}$ of DHEA, were weighed before being crushed by a mechanical grinder with the average weight of one tablet being $300.69 \mathrm{mg}$. After that, $28.7 \mathrm{mg}$ of the crushed tablet mass was weighted and added to $20 \mathrm{~mL}$ of the mobile phase (solvent), followed by 10 minutes of sonication in an ultrasonic bath with intermittent stirring and the subsequent solution was then diluted up to 50 $\mathrm{mL}$ in a volumetric flask [3]. Finally, the resultant solutions were filtered through a membrane filter with pore size of $0.45 \mu \mathrm{m}$ and injected into the HPLC instrument.

\section{Method validation}

\section{Linearity}

Stock solutions of DHEA with concentrations of $0.5,0.25,0.125$, and $0.0625 \mathrm{mg} / \mathrm{mL}$ were prepared as mentioned in Preparation of the 
standard solutions of DHEA. The data of peak area versus the concentration of DHEA were then subjected to linear regression analysis using Microsoft $®$ Excel $囚$.

\section{Precision}

Intra-day and inter-day precision values were determined by analyzing samples five times a day on five separate days. Precision was expressed as a relative standard deviation (RSD) values.

\section{Detection and quantification limits}

The mobile phase was injected six times and the noise level was determined to estimate the limits of both detection and quantification. The limit of detection was considered three times the noise value, whilst the limit of quantification was considered ten times the noise value.

\section{RESULTS}

\section{Method optimization}

Various conditions were optimized during the method development to achieve appropriate, fast, and accurate method for the determination of DHEA in dietary supplements. Different mobile phases were tested, all composed of different ratios of methanol and water and detection was carried out at different wavelengths. Mobile phase composed of methanol:water (70:30 v/v) at a flow rate of $1 \mathrm{~mL} / \mathrm{min}$ at $210 \mathrm{~nm}$ generated a sharp peak at a reasonable retention time (ca. $10.8 \mathrm{~min}$ ) in both the standard DHEA solution and the tested DHEA dietary supplement solution (Figure 2 and Figure 3).

\section{Validation}

Linearity was determined for the used chromatographic system at a concentration range of $0.0625-0.5 \mathrm{mg} / \mathrm{mL}$. The peak area was plotted against the concentration to generate a calibration curve, where the absolute coefficient of correlation was 0.9997 and a linear relationship was noticed. In addition, the regression equation was: $y=294.8 x$.

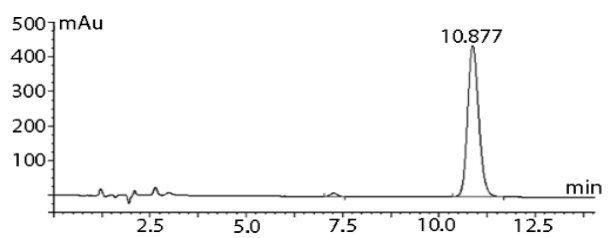

Figure 2: Chromatogram of a standard $0.5 \mathrm{mg} / \mathrm{mL}$ solution of DHEA $\left(t_{\mathrm{R}}=10.877 \mathrm{~min}\right)$

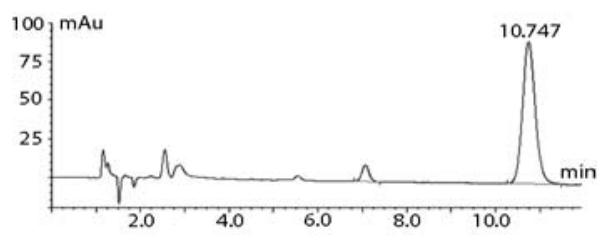

Figure 3: Chromatogram of a DHEA dietary supplement solution $\left(t_{R}=10.747 \mathrm{~min}\right)$, with a concentration of $0.574 \mathrm{mg} / \mathrm{mL}$ of the crushed tablet mass that corresponded to $0.106 \mathrm{mg} / \mathrm{mL}$ of DHEA after using the created calibration curve to calculate the concentration of DHEA in the solution of the tablet mass

The system suitability parameters are presented in Table 1. The table included both the intraday and the interday precisions, both expressed as repeatability of peak areas and retention time. Moreover, both the tailing factor and number of theoretical plates were used as tools to assess the precision of the proposed method. As the table shows, all the mentioned values exhibited good precision as revealed by their relative standard deviation (RSD) values, indicating the proposed method to be precise. Furthermore, both detection and quantification limits (LOD and LOQ) were calculated as $50 \mathrm{ng} / \mathrm{mL}$ and 166.7 $\mathrm{ng} / \mathrm{mL}$, respectively. In addition, the proposed method demonstrated good resolution as indicated by the values presented in Table 1.

Table 1: System suitability parameters

\begin{tabular}{|c|c|c|c|}
\hline \multicolumn{2}{|c|}{ Parameter } & $\begin{array}{l}\text { DHEA standard } \\
(0.5 \mathrm{mg} / \mathrm{mL})\end{array}$ & $\begin{array}{c}\text { DHEA as a } \\
\text { dietary } \\
\text { supplement } \\
(0.106 \mathrm{mg} / \mathrm{mL})\end{array}$ \\
\hline \multirow{2}{*}{ 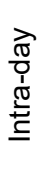 } & $\begin{array}{l}\text { Area } \\
\text { under the } \\
\text { peak }\end{array}$ & $\begin{array}{c}143.93 \\
R S D=1.73 \%\end{array}$ & $\begin{array}{c}29.13 \\
\mathrm{RSD}=2.93 \%\end{array}$ \\
\hline & $t_{\mathrm{R}}(\min )$ & $\begin{array}{c}10.93 \\
\mathrm{RSD}=0.76 \%\end{array}$ & $\begin{array}{c}10.82 \\
\mathrm{RSD}=0.84 \%\end{array}$ \\
\hline \multirow{2}{*}{ 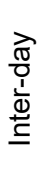 } & $\begin{array}{l}\text { Area } \\
\text { under the } \\
\text { peak }\end{array}$ & $\begin{array}{c}142.75 \\
\text { RSD }=1.57 \%\end{array}$ & $\begin{array}{c}28.07 \\
\mathrm{RSD}=4.27 \%\end{array}$ \\
\hline & $t_{R}(\min )$ & $\begin{array}{c}10.96 \\
\text { RSD }=1.52 \%\end{array}$ & $\begin{array}{c}10.93 \\
\text { RSD }=1.73 \%\end{array}$ \\
\hline \multicolumn{2}{|c|}{ Tailing factor } & $\begin{array}{c}1.16 \\
\mathrm{RSD}=0.99 \%\end{array}$ & $\begin{array}{c}1.10 \\
\text { RSD }=0.91 \%\end{array}$ \\
\hline \multicolumn{2}{|c|}{$\begin{array}{l}\text { Number of } \\
\text { theoretical } \\
\text { plates }\end{array}$} & $\begin{array}{c}6738.6 \\
\mathrm{RSD}=3.39 \%\end{array}$ & $\begin{array}{c}7220.3 \\
\text { RSD }=3.48 \%\end{array}$ \\
\hline \multicolumn{2}{|c|}{ LOD (ng/mL) } & 50 & 50 \\
\hline \multicolumn{2}{|c|}{ LOQ (ng/mL) } & 16 & 166 \\
\hline \multicolumn{2}{|c|}{ Resolution } & & 4.1 \\
\hline \multicolumn{2}{|c|}{$t_{\mathrm{R}}(\mathrm{min})$} & 7.37 & 7.60 \\
\hline \multicolumn{4}{|c|}{$\begin{array}{l}\text { Values are presented as means. repeatability }(n=5) \text {. } \\
D H E A=\text { dehydroepiandrosterone, } t_{R}=\text { retention time, } \\
t_{R}=\text { corrected retention time, } R S D=\text { relative standard } \\
\text { deviation, } L O D=\text { detection limit, } L O Q=\text { quantification } \\
\text { limit }\end{array}$} \\
\hline
\end{tabular}

Trop J Pharm Res, February 2021; 20(2): 385 


\section{Label claim}

The constructed calibration curve was employed to calculate the actual amount of DHEA that a tablet contains. After that, label claim (L) was calculated by dividing the actual weight of DHEA by the labeled DHEA weight, using the following equation:

$L(\%)=(\mathrm{Wa} / \mathrm{WI}) 100$

where $\mathrm{Wa}$ and $\mathrm{WI}$ are the actual and labelled weights of DHEA, respectively.

Repeatability and precision (as designated by RSD values) for DHEA label claim are shown in Table 2.

Table 2: Label claim of DHEA in dietary supplement tablets

\begin{tabular}{lcc}
\hline $\begin{array}{l}\text { Labeled } \\
\text { DHEA } \\
\text { content }\end{array}$ & $\begin{array}{c}\text { Calculated DHEA } \\
\text { content }\end{array}$ & Label claim (\%) \\
\hline $50 \mathrm{mg}$ & $54.1 \mathrm{mg}$ & 108.1 \\
$50 \mathrm{mg}$ & $54.4 \mathrm{mg}$ & 108.7 \\
$50 \mathrm{mg}$ & $54.5 \mathrm{mg}$ & 108.9 \\
& Mean $=54.3$ & Mean $=108.6$ \\
& RSD $0.38 \%$ & RSD $=0.38 \%$ \\
\hline
\end{tabular}

DHEA = dehydroepiandrosterone, $R S D=$ relative standard deviation

\section{DISCUSSION}

The value of this work originated from its simplicity and the low cost of the presented method- implementing a C18 stationary phase with an isocratic mobile phase and a flow rate of $1 \mathrm{~mL} / \mathrm{min}$ coupled to a UV detector to obtain an analyte peak at $10.8 \mathrm{~min}$. As mentioned earlier, a lot of the currently employed methods used to determine DHEA in food supplements rely on normal stationary phases that are of higher costs compared to reversed stationary phases and limited selection of solvents. On the other hand, others use buffers in mobile phases which includes additional lab work, costs and risk factors to the separation process which are all avoided in our proposed method. For example, Ivanova et al used a diol stationary phase in the separation process with the aid of an isocratic flow of acetonitrile:water $(98: 2 \mathrm{v} / \mathrm{v})$ at $1 \mathrm{~mL} / \mathrm{min}$, but the peak of DHEA was only obtained after 31 min of elution [3].

Meanwhile, Aboul-Enein et al used a C18 reversed phase HPLC column and eluted DHEA after $6.8 \mathrm{~min}$ at a flow rate of $1 \mathrm{~mL} / \mathrm{min}$. However, the implemented mobile phase had to be adjusted to $\mathrm{pH} 5$ using $5 \mathrm{~g} / \mathrm{L}$ sodium acetate buffer solution [12]. Moreover, Thompson et al implemented reversed phase HPLC to achieve the separation of DHEA in dietary supplement products, but their method relied on the use of phosphate buffer solution to adjust the $\mathrm{pH}$ to 3.50 [1]. In addition, Rush et al used a reverse-phase HPLC system with acetonitrile:water (45:55 v/v) as a mobile phase with detection was carried out at $207 \mathrm{~nm}$. The DHEA was eluted at $8.0 \mathrm{~min}$. However, acetonitrile is more costly than methanol [13]. Nonetheless, the present work utilized an isocratic, a C18 reversed phase column and a mobile phase composed of methanol and water. Thus, making this method of analyzing DHEA simple, cost efficient and could be carried out with no major limitations in labs that analyzes nutraceuticals, where the simplest method of analysis is always sought after.

\section{CONCLUSION}

Interest in dietary supplements has been growing over the decades, hence, robust analytical techniques are needed as quality control tools for these products. DHEA is no exception as it is increasingly used to slow signs of aging, improve physical performance and to increase sex hormone levels. A method for determining DHEA concentration in dietary supplements using a reversed HPLC stationary phase is here proposed as a quality control tool. The developed method is simple, cost-effective, reproducible, and ensures rapid and successful separation of DHEA from the accompanying excipients.

\section{DECLARATIONS}

\section{Acknowledgement}

The authors thank Hamdi Mango Center for Scientific Research (HMCS) and The Deanship of Scientific Research, The University of Jordan, for technical and the financial support. This work is dedicated to the memory of Kamal M Mansi.

\section{Conflict of interest}

There is no conflict of interest with regard to this work.

\section{Contribution of authors}

We declare that this work was done by the authors named in this article and all liabilities pertaining to claims relating to the content of this article will be borne by the authors. Yahia $Z$ Tabaza and Kamal M Mansi analyzed the results and took part in writing and revising the manuscript. Hanan A Azzam, Farah F Al- 
Mamoori and Ali M Al-Samydai conducted the laboratory work. Talal A Aburjai designed the study, helped in analyzing the results and revised the manuscript. All authors read and approved the final manuscript.

\section{Open Access}

This is an Open Access article that uses a funding model which does not charge readers or their institutions for access and distributed under the terms of the Creative Commons Attribution License (http://creativecommons.org/licenses/by/ 4.0) and the Budapest Open Access Initiative (http://www.budapestopenaccessinitiative.org/rea d), which permit unrestricted use, distribution, and reproduction in any medium, provided the original work is properly credited.

\section{REFERENCES}

1. Thompson RD, Carlson M. Liquid chromatographic determination of dehydroepiandrosterone (DHEA) in dietary supplement products. J AOAC Int. 2000; 83(4): 847-857.

2. Samaras $N$, Samaras $D$, Frangos E, Forster A, Philippe J. A review of age-related dehydroepiandrosterone decline and its association with well-known geriatric syndromes: is treatment beneficial? Rejuvenation Res. 2013; 16(4): 285-294.

3. Ivanova $S D$, Ivanov $K V$, Mladenov $R$, Obreshkova $D P$, Ivanova $S$, Stoyanov $P$. HPLC detection of dehydroepiandrosterone in food additives by using normal phase HPLC. Scr Sci Pharm. 2016; 3(1): 54-59.

4. Black $T$. Does the ban on drugs in sport improve societal welfare? Int Rev Sociol Sport. 1996; 31(4): 367-381.

5. Mareck U, Geyer H, Opfermann G, Thevis M, Schänzer $W$. Factors influencing the steroid profile in doping control analysis. J Mass Spectrom. 2008; 43(7): 877891.

6. Blackledge RD. Bad science: the instrumental data in the Floyd Landis case. Clin Chim Acta. 2009; 406(1-2): 813.

7. Fragkaki AG, Angelis YS, Tsantili-Kakoulidou A, Koupparis M, Georgakopoulos C. Schemes of metabolic patterns of anabolic androgenic steroids for the estimation of metabolites of designer steroids in human urine. J Steroid Biochem Mol Biol. 2009; 115(1-2): 4461.

8. Baume N, Mahler N, Kamber M, Mangin P, Saugy M. Research of stimulants and anabolic steroids in dietary supplements. Scand J Med Sci Sports. 2006; 16(1): 4148.

9. Kushnir MM, Blamires T, Rockwood AL, Roberts WL, Yue B, Erdogan E, Bunker AM, Meikle AW. Liquid chromatography-tandem mass spectrometry assay for androstenedione, dehydroepiandrosterone, and testosterone with pediatric and adult reference intervals. Clin Chem. 2010; 56(7): 1138-1147.

10. Alexaki VI, Fodelianaki G, Neuwirth A, Mund C, Kourgiantaki A, leronimaki E, Lyroni K, Troullinaki M, Fujii C, Kanczkowski $W$, et al. DHEA inhibits acute microglia-mediated inflammation through activation of the TrkA-Akt1/2-CREB-Jmjd3 pathway. Mol Psychiatry. 2018; 23(6): 1410-1420.

11. Gergely A, Szász G, Szentesi A, Gyimesi-Forrás K, Kökösi J, Szegvári $D$, Veress $G$. Evaluation of $C D$ detection in an HPLC system for analysis of DHEA and related steroids. Anal Bioanal Chem. 2006; 384(7-8): 1506-1510.

12. Aboul-Enein HY. High performance liquid chromatographic analysis of dehydroepiandrosterone and its pharmaceutical tablet formulation. Biomed Chromatogr. 2004; 18(1): 6-9.

13. Rush SD, Vernak C, Zhao F. A Pilot Stability Study of Dehydroepiandrosterone Rapid-dissolving Tablets Prepared by Extemporaneous Compounding. Int $\mathrm{J}$ Pharm Compd. 2017; 21(1): 83-87. 